\title{
A educação especial no âmbito do planejamento orçamentário do município de Vitória, Espírito Santo
}

\author{
Special education in the municipal budget planning in the municipality of \\ Vitória, Espírito Santo, Brazil \\ La educación especial en el alcance de la planificación presupuestaria de la \\ ciudad de Vitória, Espírito Santo \\ MARILEIDE GONÇALVES FRANÇA
}

Resumo: Este texto analisa a ação do Poder Público no provimento de recursos à educação especial no âmbito do planejamento orçamentário do município de Vitória, Espírito Santo, no período de 2008 a 2013. Entende o Estado como espaço público marcado pela correlação de forças entre classes que compõem a sociedade e participam da formulação de políticas públicas. Para tanto, realiza pesquisa documental e evidencia que a educação especial integrava o orçamento municipal. Contudo, os valores irrisórios previstos para essa modalidade estavam subdimensionados e/ou agregados às outras etapas de ensino.

Palavras-chave: Educação especial; Estado; planejamento; orçamento.

Abstract: This paper analyzes the action of public authorities while allocating funds to special education within the boundaries of budget planning in the municipality of Vitoria, Espírito Santo, Brazil, between 2008 and 2013. It understands the State as a public space marked by correlation of forces between classes that make up society and participate in the creation of public policies. For this purpose, the study employs documental research. It reveals that special education was part of the municipal budget. However, the ridiculous amounts available for this modality were undersized and/or bound to other stages of education.

Keywords: Special education; State; planning; budget.

Resumen: Este texto analiza la acción del Poder Público en las provisiones de recursos a la educación especial en el ámbito de la planificación presupuestaria de la ciudad de Vitoria, Espirito Santo, en el período de 2008 a 2013. Entiende el Estado como espacio público marcado por la correlación de fuerzas entre clases que componen la sociedad y participan de la formulación de políticas públicas. Para tanto, realiza la investigación documental. Evidencia que la educación especial integraba el presupuesto municipal. Sin embargo, los valores irrisorios previstos a esa modalidad estaban subdimensionados y/o agregados a otras etapas de la enseñanza.

Palabras clave: Educación especial; Estado; planificación; presupuesto. 


\section{INTRODUÇÃO}

A Constituição Federal de 1988 (CF/1988) incorporou demandas importantes relacionadas aos direitos de cidadania, como o direito à educação. No art. 205, afirma-se a responsabilidade do Estado pela oferta da educação: "A educação, direito de todos e dever do Estado e da família, será promovida e incentivada com a colaboração da sociedade, visando ao pleno desenvolvimento da pessoa, seu preparo para o exercício da cidadania e sua qualificação para o trabalho" (BRASIL, 1988). No art. 208, inciso III, estabelece o "atendimento educacional especializado aos portadores de deficiência, preferencialmente na rede regular de ensino" (Idem). Nesse sentido, o compromisso do Poder Público com a educação básica e torna explícito, desde a educação infantil se estendendo às demais etapas e modalidades de ensino.

Na Lei de Diretrizes e Bases da Educação de 1996 (BRASIL, 1996), ao se estabelecer a educação especial como modalidade de educação escolar, oferecida preferencialmente na rede regular de ensino, assegura-se apoio especializado aos alunos com deficiência, transtornos globais de desenvolvimento (TGD) e altas habilidades/superdotação ${ }^{1}$, oferecido na escola regular e o atendimento educacional realizado em classes, escolas ou serviços especializados. $\mathrm{Na}$ LDB/1996 também foi estabelecido o dever do Estado com a educação mediante a garantia de "padrões mínimos de qualidade de ensino, definido como a variedade e quantidade mínimas, por aluno, de insumos indispensáveis ao desenvolvimento do processo de ensino-aprendizagem (BRASIL, 1996, art. 4 , inciso IX). Essa ideia articula-se à necessidade de investir esforços no intuito de se garantirem a oferta e melhores condições de ensino.

No Brasil, a universalização do direito à educação apresentou características peculiares, considerando-se sua formação social, política, econômica e cultural. No que se refere à trajetória histórica da educação especial, ou seja, à conquista dos direitos à educação das pessoas com deficiência, TGD e altas habilidades/superdotação, evidenciamos configurações específicas no tocante a seu processo de concretização. A educação especial iniciou-se atrelada às ações isoladas, desenvolvidas no Ministério da Educação (MEC), voltadas às instituições privadas de caráter assistencial, não consideradas pertencentes à rede de ensino brasileira, mas financiadas, em grande parte, com verbas públicas da educação. Só, recentemente (no final dos anos 1950 e início da década de 1960), ela se tornou política pública, isto é, forma de materialização da intervenção estatal na oferta e na manutenção do atendimento educacional especializado - mantido

1 População elegível para a educação especial pela Lei no 12.796 , de 4 de abril de 2013. 
e administrado pelo Estado - nas escolas públicas dos sistemas educacionais brasileiros (KASSAR, 2001).

A educação especial como política pública, isto é, "como forma de intervenção estatal na oferta e proteção de determinado direito de cidadania" (CURY, 2007, p. 832) pressupõe investimento financeiro por parte do Poder Público para garantir sua concretização e oferecer serviços públicos voltados ao atendimento das pessoas com deficiência, TGD e altas habilidades/superdotação. Nessa direção, ela integra o sistema de financiamento da educação no Brasil.

Os recursos destinados à educação e às demais modalidades de ensino, assim como todas as despesas do Poder Púbico devem estar previstos no orçamento público. Partimos do pressuposto que o "orçamento público é a materialização da ação planejada do Estado para manutenção de suas atividades e execução de seus projetos, assim como permite a visualização do direcionamento das ações do Estado e de suas efetivas prioridades" (SALVADOR, 2010, p. 49). Nesse contexto, o orçamento constitui elemento importante para compreender o financiamento educacional, pois é um instrumento técnico, de planejamento do Estado, que vai além da sua estruturação contábil, refletindo a "correlação de forças sociais e os interesses envolvidos na apropriação dos recursos públicos, bem como a definição de quem vai arcar com o ônus do financiamento dos gastos orçamentários" (Idem, p. 172).

O dimensionamento desses gastos possibilita entender a importância dada a cada política pública no contexto político, social e econômico do país. No nosso caso em particular, o estudo do orçamento vinculado à educação nos permitirá conhecer o quantitativo de recursos que está sendo destinado à educação especial no âmbito do município. Nessa perspectiva, Salvador (2010) salienta que "o orçamento é um instrumento privilegiado, que deve assegurar e expressar os requisitos de cumprimento dos direitos, refletindo as prioridades definidas pelo governo na execução e na escolha das políticas públicas” (p. 180).

Este texto analisa a ação do Poder Público no provimento de recursos à educação especial no âmbito do planejamento orçamentário do município de Vitória, Espírito Santo, nos anos de 2008 a 2013. O período considerado compreendeu o ano de 2008, pois considera as mudanças ocorridas com o novo padrão de financiamento da educação adotado através da implantação do Fundo de Manutenção e Desenvolvimento da Educação Básica e de Valorização dos Profissionais da Educação (Fundeb), iniciada em 2007, que passou a abranger todas as etapas e modalidades de ensino; e as alterações na legislação da educação especial, com a promulgação da Política Nacional de Educação especial na Perspectiva da Educação Inclusiva- PNEE-EI (BRASIL, 2008); e o ano de 2013, último ano de dados consolidados no banco de dados do município de Vitória. 
Para o desenvolvimento de nosso trabalho, propusemos a pesquisa documental, na tentativa de compreender e analisar como se caracterizava a Educação Especial no planejamento orçamentário do município de Vitória, capital do Estado do Espírito Santo. Partimos da compreensão de que os documentos públicos constituem possíveis fontes de onde se podem extrair dados para investigar as políticas educacionais. Assim, verificamos, inicialmente, os dados disponíveis nos meios eletrônicos, especificamente, no portal de transparência do município, os instrumentos formais de planificação orçamentária. Posteriormente, analisamos os documentos produzidos pelos órgãos públicos: balanços da execução financeira dos municípios, relatórios anuais de atividades, além de documentos oficiais, como resoluções, portarias e decretos referentes à Educação Especial e ao financiamento da educação do sistema de ensino municipal.

\section{A EDUCAÇÃO ESPECIAL NO ÂMBITO DO ESTADO BRASILEIRO}

No Brasil, nos últimos anos, percebemos inúmeras mudanças nas políticas de educação especial voltadas aos alunos com deficiência, TGD e altas habilidades/superdotação no contexto dos sistemas educacionais. Segundo Garcia e Michels (2011), há um movimento claro de intervenção estatal na política educacional no que se refere à educação do público da educação especial, por meio "da presença do Estado na criação de equipamentos públicos de educação especial”'(p. 116), nas redes de ensino estaduais e municipais.

Em relação às políticas de educação especial desenvolvidas nas últimas décadas, Plestch (2012) afirma que houve uma ampliação de investimentos financeiros voltados à garantia dos direitos das pessoas com deficiência, TGD, altas habilidades/superdotação, no contexto de implementação de políticas de inclusão social e educacional direcionadas a diferentes grupos sociais. No caso da educação especial, as iniciativas se desenvolveram por meio de políticas e programas voltados à Educação Básica e ao Ensino Superior.

Em 2007, o Decreto n ${ }^{\circ}$ 6.094, de 24 de abril, estabeleceu as diretrizes do Plano de Metas Compromisso Todos pela Educação (BRASIL, 2007a) e o Plano de Ações Articuladas (PAR), definindo a participação da União, do Distrito Federal, dos estados e dos municípios em regime de colaboração e ação compartilhada com as famílias e comunidades, mediante programas e ações de assistência técnica e financeira, em favor da melhoria da qualidade da Educação Básica. Nesse contexto, foi lançado pelo MEC o Plano de Desenvolvimento da Educação (PDE) (BRASIL, 2007a), abrangendo diferentes ações destinadas às etapas e modalidades de ensino, além de medidas de apoio e infraestrutura. Nesse documento, a educação especial 
foi representada pelos seguintes programas: Programa de Salas de Recursos Multifuncionais; Programa Incluir: de Acessibilidade na Educação Superior; Programa Olhar Brasil; e o Programa de Acompanhamento e Monitoramento do Acesso e Permanência na Escola das Pessoas com Deficiência Beneficiárias do Benefício de Prestação Continuada da Assistência Social. Cumpre destacar que esses programas, desenvolvidos pelo governo federal, eram financiados pelos recursos do PDE e pelo Plano de Aceleração do Crescimento (PAC), tendo como eixos a acessibilidade arquitetônica dos prédios escolares, a implantação de salas de recursos e a formação docente para o atendimento educacional especializado.

Em 2008, foi publicado o documento PNEE-EI/2008 (BRASIL, 2008), que passou a orientar os sistemas de ensino para a organização de serviços e recursos de educação especial. O objetivo era promover respostas às necessidades educacionais especiais dos alunos com deficiência, TGD e altas habilidades/ superdotação, reafirmando a Educação Especial como modalidade da educação escolar que, portanto, perpassa todos os níveis de ensino, desde a Educação Infantil até a Educação Superior, abrangendo também as modalidades educação especial e educação de jovens e adultos (EJA).

No intuito de garantir a implementação da PNEE-EI/08 (BRASIL, 2008), que traduzia certa expectativa em relação à ampliação de recursos e serviços como apoio ao processo de escolarização dos alunos com deficiência, TGD e altas habilidades/superdotação nas unidades de ensino, foi aprovado o Decreto $\mathrm{n}^{\mathrm{0}}$ 7.611, de 17 de novembro de 2011, com a finalidade de garantir o compromisso da União na prestação de apoio técnico e financeiro aos sistemas públicos de ensino do Distrito Federal, dos estados e dos municípios, para o atendimento educacional especializado. Assim, a partir de 2010, os alunos com deficiência, TGD e altas habilidades/superdotação passaram a ser contabilizados duplamente no âmbito do Fundeb, quando matriculados em classes comuns do ensino regular e também no atendimento educacional especializado, podendo este ser realizado na mesma escola que o aluno frequenta, em outra do seu entorno, ou por instituições comunitárias, confessionais ou filantrópicas sem fins lucrativos.

Cabe destacar, ainda, que os princípios definidos na atual política do governo federal foram confirmados, em 2010, pela Conferência Nacional de Educação (Conae), que mobilizou, no território nacional, diferentes grupos sociais na discussão de diretrizes e estratégias para a construção do PNE, o novo Plano Nacional de Educação (LAPLANE; PRIETO, 2010). Após quase quatro anos de tramitação entre o MEC e o Congresso Nacional, o PNE foi aprovado pela Lei $\mathrm{n}^{\circ}$ 13.005, de 25 junho de 2014, com 14 artigos, 20 metas e 254 estratégias, que, durante os próximos dez anos, orientarão as diretrizes e as 
políticas educacionais. No PNE 2014-2024, a educação especial foi contemplada na Meta 4, cujo compromisso assumido para o decênio é:

Universalizar, para a população de 4 (quatro) a 17 (dezessete) anos com deficiência, transtornos globais do desenvolvimento e altas habilidades ou superdotação, o acesso à educação básica e ao atendimento educacional especializado, preferencialmente na rede regular de ensino, com a garantia de sistema educacional inclusivo, de salas de recursos multifuncionais, classes, escolas ou serviços especializados, públicos ou conveniados (BRASIL, 2014).

Cumpre destacar que o processo de tramitação e aprovação do PNE 2014-2024contou mais uma vez com as correlações de forças historicamente existentes na definição de políticas da educação especial, marcada pelas disputas pela obtenção dos recursos públicos destinados à educação especial. Ficou evidente a forte capacidade das entidades privadas de influenciar os parlamentares na garantia da manutenção do financiamento das instituições comunitárias, confessionais ou filantrópicas sem fins lucrativos por meio de convênios com o Poder Público, na oferta de serviços de educação especial.

Assim, na tentativa de discutir a relação existente entre as políticas de educação especial desencadeadas pelo governo federal e o financiamento da educação especial, buscamos analisar essa modalidade de ensino no âmbito do planejamento orçamentário em um município brasileiro. Antes, porém, de compreendermos esse processo, torna-se necessário conhecer como se realiza o processo de elaboração do orçamento público no Brasil.

\section{O ORÇAMENTO PÚBLICO NO ÂMBITO DO ESTADO BRASILEIRO}

A Lei $\mathrm{n}^{\circ}$ 4.320, de 17 de março de 1964, que fixa as normas gerais para elaboração dos orçamentos públicos e para o controle das finanças públicas, em seu art. $2^{\circ}$, estabelece que "a Lei do Orçamento conterá a discriminação da receita e da despesa de forma a evidenciar a política econômica financeira e o programa de trabalho do governo, obedecidos os princípios de unidade, universalidade e anualidade" (BRASIL, 1964).

Antes de 1988, o orçamento estava todo centralizado no Poder Executivo, com esvaziamento do Poder Legislativo. A CF/1988, ao ratificar no campo das finanças públicas os processos de reordenamento institucional e de unificação do orçamento, ampliou o fortalecimento da Federação e do papel do Congresso Nacional, recuperando as prerrogativas do Poder Legislativo em matéria orçamentária (SALVADOR, 2010). Na tentativa de recuperar o papel 
de planejador do Estado, foram criadas mais duas peças orçamentárias: o Plano Plurianual (PPA) e a Lei de Diretrizes Orçamentárias (LDO).

A partir da CF/1988, em seu art.165, o ciclo orçamentário passou a ser composto por três instrumentos distintos, mas interligados: o PPA, a LDO e a Lei Orçamentária Anual (LOA), cujo objetivo é integrar as atividades de planejamento e orçamento, bem como assegurar a execução das políticas na União, no Distrito Federal, nos estados e nos municípios. Desse modo, cabe ao Poder Legislativo apreciar esses instrumentos, no âmbito de cada esfera administrativa, e aproválos.

As principais regulamentações legais parao denominadocicloorçamentário brasileiro são a Lei nº 4.320/1964, a CF/1988 e a Lei Complementar n 101, de 4 de maio de 2000, denominada "Lei de Responsabilidade Fiscal", que estabelece normas de finanças públicas voltadas para a responsabilidade na gestão fiscal e dá outras providências. Assim, segundo Polo (1999), quanto ao planejamento e à execução orçamentária, a CF/1988 consagrou o princípio de que o orçamento público integra um sistema em que as ações de governo deveriam ser definidas em processo amplo de planejamento, no qual se estabelecem, antecipadamente, as diretrizes, os objetivos e as metas da administração pública por certo período de tempo.

O PPA define diretrizes, objetivos e metas da administração para um período de quatro anos, com ações orçamentárias e custos da administração pública, para as despesas de capital e outras delas decorrentes, e para as relativas aos programas de duração continuada. É constituído por um conjunto de programas, por meio dos quais os governos tentam alcançar os objetivos estabelecidos no plano, de acordo com as demandas de cada esfera do governo.

Com vigência de um ano, a LDO se pauta nos grandes princípios e critérios apontados no PPA, visto que ela antecipa a discussão orçamentária, define metas e prioridades para o ano seguinte e anuncia as metas fiscais, ou seja, o montante a ser arrecadado e como será despendido. A LOA deve estimar as receitas de tributos e fixar as despesas que as administrações públicas da União, dos estados e dos municípios estão autorizadas a executar no exercício financeiro. Portanto, cada ente federado deve planejar suas receitas e despesas, controlá-las e limitá-las quando as metas se mostrarem comprometidas. Nessa perspectiva, os recursos destinados à educação, assim como todas as demais despesas do Poder Público, também devem estar previstos no PPA, como diretrizes gerais; na LDO, como diretrizes orientadoras para o conjunto de receitas e despesas; e na LOA, onde deverão estar contemplados de modo detalhado para sua utilização (GOUVEIA, 2002). 
A LDB/1996 estabeleceu procedimento para o acompanhamento da execução orçamentária das despesas com educação, bem como do gerenciamento dos recursos da educação. De acordo com o art. 69, \4 4" " as diferenças entre a receita e a despesa previstas e as efetivamente realizadas que resultem no não atendimento dos percentuais mínimos obrigatórios, serão apuradas e corrigidas a cada trimestre do exercício financeiro". Assim, ressalta que os recursos educacionais, além de se articularem com as metas fixadas nos documentos orçamentários, devem obedecer à vinculação constitucional de recursos. Entretanto, de acordo com Polo (1999), o orçamento tem sido pouco utilizado como uma das etapas conceituais do processo de planejamento para alocação racional e gerenciamento de recursos públicos, visando à prestação de serviços à população. Na mesma direção, Salvador (2010) salienta a manutenção da "precariedade no acompanhamento da execução orçamentária e a falta de parâmetros que estabeleçam com clareza os objetivos e os compromissos da programação financeira" (p. 177).

Nesse sentido, concordamos com o autor quando diz que o "orçamento não se limita a uma peça técnica e formal ou a um instrumento de planejamento; ele é, desde suas origens, uma peça de cunho político” (Idem, p.178). Assim, ele representa a correlação de forças sociais e políticas da sociedade, orienta as negociações relacionadas ao financiamento do Estado, servindo como instrumento de controle, direcionamento dos gastos e prioridades de políticas públicas. Conforme Oliveira (2001), o orçamento revela sobre a classe ou fração de classe sobre a qual recai o maior ou o menor ônus da tributação e as classes que mais se beneficiam com os gastos orçamentários; portanto, ele envolve negociações dos representantes políticos, uma vez que o orçamento é a expressão das reivindicações das classes que elas representam. Assim, é fundamental analisarmos no planejamento orçamentário de Vitória, estado do Espírito Santo, se as demandas e necessidades do alunado da educação especial estavam contempladas entre as prioridades políticas do município.

Nesse contexto, cumpre destacar a importância da gestão democrática dos recursos públicos, que, segundo Melchior (1991), constituiu-se pela via exclusiva da participação dos interessados nos órgãos decisórios. Na educação, uma das possibilidades seria a participação no processo de gestão do financiamento em educação, que envolve o planejamento orçamentário, discutido anteriormente, e o controle social dos recursos públicos. Nesse sentido, defendemos uma perspectiva de gestão que considere a implementação de mecanismos de participação nos processos de decisão nas diferentes instâncias do Estado e na formulação de políticas públicas capazes de assegurar a todos o direito social da educação.

No ordenamento constitucional e infraconstitucional brasileiro, está prevista a função de fiscalização para cada uma das entidades da administração 
direta e indireta das esferas do Poder Público, por meio dos sistemas de controle interno e externo, e, ainda, há a previsão de qualquer cidadão poder examinar as contas do governo e questionar sua legitimidade.

A Constituição Federal (BRASIL, 1988) (Arts. $5^{\circ}$ e $6^{\circ}$ ), na tentativa de garantir a democratização da gestão do Estado, menciona dois procedimentos para o aumento da participação da população em suas instâncias: "o acesso à informação e a participação de representantes nos setores específicos em órgãos da administração pública" (ADRIÃO; CAMARGO, 2007, p. 65). Nesse sentido, a Constituição assegura o direito do cidadão de participar da gestão, inclusive no controle dos recursos públicos. Cabe destacar a promulgação da nova Lei $\mathrm{n}^{\mathrm{o}}$ 12.527, de 18 de novembro de 2011, que dispõe sobre os procedimentos a serem observados pela União, estados, Distrito Federal e municípios, com o fim de garantir o acesso às informações previstas na Constituição Federal, a partir do desenvolvimento de uma cultura de transparência e controle social da administração pública. Assim, a Lei prevê, no art. 5, que "É dever do Estado garantir o direito de acesso à informação, que será franqueada, mediante procedimentos objetivos e ágeis, de forma transparente, clara e em linguagem de fácil compreensão" (BRASIL, 2011b), inclusive com o uso da tecnologia de informação.

\section{A EDUCAÇÃO ESPECIAL NO PLANEJAMENTO ORÇAMENTÁRIO DO MUNICÍPIO DE VITÓRIA}

No PPA de 2006 a 2009, aprovado pela Lei no 6.375, de 14 de setembro de 2005, do município de Vitória, encontramos cinco programas voltados à educação e vinculados à Seme-Vitória. Entre eles, destacamos o programa Universalização do Acesso ao Ensino Fundamental com Qualidade, que tinha como objetivo "garantir acesso e educação com qualidade social às crianças, jovens e adultos do município de Vitória que demandam o Ensino Fundamental" (VITÓRIA, 2005). Entre as ações previstas no programa, uma fazia menção à educação especial: Inclusão de Crianças, Adolescentes, Jovens e Adultos com Necessidades Especiais. A meta consistia em ampliar o quantitativo desses alunos no ensino fundamental. Cabe ressaltar que esse programa tentava atender à Lei no 11.274, de 6 de fevereiro de 2006 (BRASIL, 2006), que altera a redação dos artigos 29, 30, 32 e 87 da LDB/1996, que estabelece as diretrizes e bases da educação nacional, dispondo sobre a educação de nove anos para o ensino fundamental, com matrícula obrigatória a partir dos seis anos de idade.

Na Lei $n^{\circ} 7.845$, de 9 de dezembro de 2009 (VITÓRIA, 2009a), que dispunha sobre o PPA para o período de 2010 a 2013, identificamos quatro 
programas vinculados à Seme Vitória. Porém, encontramos, no documento, somente o programa Acesso e Permanência à Educação Básica com Qualidade com alusão à educação especial, tendo ele a finalidade de

\footnotetext{
Garantir acesso à Educação Básica nas etapas da Educação Infantil, Ensino Fundamental e nas modalidades de Educação de Jovens e Adultos (EJA) e de Educação Especial (EE), com garantia das condições de permanência e de qualidade socialmente referenciada, considerando os espaços formais e os espaços não formais de acesso ao conhecimento científico-cultural. (VITÓRIA, 2009a).
}

Entre as ações, destacava-se a de Acompanhamento e atendimento na Modalidade de Educação Especial, cujos objetivos eram assegurar o direito à educação dos alunos com deficiência, TGD e altas habilidades/superdotação e garantir condições objetivas para o atendimento com qualidade aos referidos alunos, tanto na classe comum do ensino regular quanto nos serviços de apoio especializados, bem como ampliar os serviços oferecidos pelo sistema municipal, por meio das salas de recursos multifuncionais, do Cedet e da política de educação bilíngue. Nesse sentido, notamos que a educação especial foi contemplada nos planejamentos da administração municipal de 2006 a 2009 e de 2010 a 2013 como programa e/ou ação, o que demonstrava a intenção política do município em relação a essa modalidade de ensino, considerando, assim como Salvador (2012), que "o orçamento público é o que garante concretude à ação planejada do Estado e espelha as prioridades das políticas públicas que serão priorizadas pelo governo" (p. 5).

Nas Leis de Diretrizes Orçamentárias para os anos de 2008 a 2013, o texto era único e mais genérico, em termos de dados, não apresentando informações detalhadas referentes às áreas, secretarias e modalidades de ensino, como a educação especial. Encontramos apenas uma menção referente à educação na parte de objetivos, que orientaria a definição de prioridades e metas do município: "promover a universalização do acesso à educação infantil e ao ensino fundamental com qualidade" (VITÓRIA, 2007, art. $2^{\circ}$, \ $2^{\circ}$, inciso II;2008a, art. $2^{\circ}$, \ $2^{\circ}$, inciso II; 2009b, art. $2^{\circ}$, inciso II; 2010a, art. $2^{\circ}$, inciso II; 2011a, art. $2^{\circ}$, inciso II; 2012a, art. $2^{\circ}$, inciso II). Essa prioridade pode ser explicada pela implantação do ensino fundamental de nove anos na rede municipal de Vitória nesse período.

Nas LOAs de 2008 a 2013, verificamos entre as ações da Seme-Vitória a intervenção junto às diferentes etapas e modalidades de ensino, no intuito de garantir a universalização do acesso e a inclusão de crianças, adolescentes, jovens e adultos à educação. A seguir, serão apresentados na Tabela 1 os valores previstos pela LOA à educação, no município de Vitória, nos anos de 2008 e 2013. 
Tabela 1- Valores previstos pela LOA 2008 a 2013 à educação.

\begin{tabular}{|c|c|c|c|}
\hline ANO & $\begin{array}{c}\text { FUNÇÃO EDUCAÇÃO } \\
\text { R\$ }\end{array}$ & $\begin{array}{c}\text { CORRENTES } \\
\text { R\$ }\end{array}$ & $\begin{array}{c}\text { CAPITAL } \\
\text { R\$ }\end{array}$ \\
\hline $\mathbf{2 0 0 8}$ & $311.934 .364,80$ & $283.243 .753,24$ & $28.690 .611,56$ \\
\hline $\mathbf{2 0 0 9}$ & $335.688 .876,06$ & $309.247 .132,64$ & $26.441 .743,42$ \\
\hline $\mathbf{2 0 1 0}$ & $353.552 .052,82$ & $313.143 .896,34$ & $40.408 .156,48$ \\
\hline $\mathbf{2 0 1 1}$ & $390.575 .216,40$ & $355.723 .948,76$ & $34.851 .267,64$ \\
\hline $\mathbf{2 0 1 2}$ & $383.608 .064,46$ & $363.406 .910,99$ & $20.201 .153,47$ \\
\hline $\mathbf{2 0 1 3}$ & $375.536 .721,69$ & $356.427 .484,76$ & $19.109 .236,93$ \\
\hline
\end{tabular}

Fonte: LOA, Vitória 2008, 2009, 2010, 2011, 2012 e 2013. Elaboração própria.

Valores atualizados com base no INPC/IBGE de 12/2014

$\mathrm{Na}$ LOA, era estabelecido o orçamento da educação, totalizando cerca de $\mathrm{R} \$ 312$ milhões em 2008, R \$ 336 milhões em 2009, R \$ 354 milhões em 2010, R\$ 391 milhões em 2011, R\$ 384 milhões em 2012 e R\$ 376 milhões em 2013, montante esse dividido entre despesas correntes e despesas de capital. Desse modo, cerca de $9 \%, 8 \%, 11 \%, 9 \%, 5 \%$ e $5 \%$ dos recursos, respectivamente, seriam destinados à compra de instalações, equipamentos e materiais permanentes, planejamento e execução de obras, bem como amortizações de dívida e concessões de empréstimos. O restante seria empregado para manutenção e funcionamento da rede municipal.

No anexo oito da LOA, os mesmos valores apareceram distribuídos por "Demonstrativo das Funções, Sub-Funções e Programas por Projetos, Atividades e Operações Especiais” (VITÓRIA, 2008b; 2009c, 2010b, 2011b, 2012b), o que nos possibilitou verificar o percentual previsto para ser gasto em cada uma das etapas e modalidades de ensino no município, como apresentado nas Tabelas 2 e 3.

Tabela 2 - Valores previstos pela LOA 2008 a 2013 para as etapas e modalidades de ensino

\begin{tabular}{|c|c|c|c|c|c|c|}
\hline \multirow{2}{*}{$\begin{array}{c}\text { Etapas } \\
\mathrm{e} \\
\text { Modalidades }\end{array}$} & \multicolumn{6}{|c|}{ VALORES/ANO R\$ } \\
\hline & 2008 & 2009 & 2010 & 2011 & 2012 & 2013 \\
\hline $\begin{array}{c}\text { Ensino } \\
\text { Fundamental }\end{array}$ & $211.270 .085,61$ & $222.831 .597,21$ & $182.775 .535,12$ & $218.140 .352,50$ & $213.292 .964,45$ & 195.194.347,11 \\
\hline $\begin{array}{l}\text { Educação } \\
\text { Infantil }\end{array}$ & $94.258 .518,60$ & 107.712.437,14 & $163.863 .947,22$ & $164.374 .637,23$ & $162.581 .361,43$ & $141.632 .883,67$ \\
\hline $\begin{array}{c}\text { Educação } \\
\text { Especial }\end{array}$ & $2.120 .554,76$ & $1.426 .778,36$ & $1.847 .827,24$ & $2.649 .563,43$ & $1.079 .740,59$ & $1.495 .389,20$ \\
\hline
\end{tabular}


Tabela 2 - Valores previstos pela LOA 2008 a 2013 para as etapas e modalidades de ensino

\begin{tabular}{|c|c|c|c|c|c|c|}
\hline \multirow{2}{*}{$\begin{array}{c}\text { Etapas } \\
\text { e } \\
\text { Modalidades }\end{array}$} & \multicolumn{6}{|c|}{ VALORES/ANO R\$ } \\
\hline & 2008 & 2009 & 2010 & 2011 & 2012 & 2013 \\
\hline $\begin{array}{c}\text { Educação } \\
\text { de Jovens e } \\
\text { Adultos }\end{array}$ & - & - & $286.317,91$ & $590.095,22$ & $419.123,03$ & $355.715,71$ \\
\hline $\begin{array}{l}\text { Outros (Apoio } \\
\text { administrativo) }\end{array}$ & $4.285 .205,82$ & $3.718 .063,35$ & $4.625 .922,39$ & $4.752 .102,61$ & $6.234 .874,96$ & $36.858 .386,00$ \\
\hline $\begin{array}{c}\text { Valorização e } \\
\text { Capacitação } \\
\text { dos servidores }\end{array}$ & - & - & $152.502,94$ & $68.465,41$ & - & - \\
\hline TOTAL & $311.934 .364,80$ & $335.688 .876,06$ & $353.552 .052,82$ & $390.575 .216,40$ & $383.608 .064,46$ & $375.536 .721,69$ \\
\hline
\end{tabular}

Fonte: LOA, Vitória 2008, 2009, 2010, 2011, 2012 e 2013. Elaboração própria.

Valores atualizados com base no INPC/IBGE de 12/2014

Tabela 3 - Variações dos valores previstos pela LOA 2008 a 2013 para as etapas e modalidades de ensino

\begin{tabular}{|c|c|c|c|c|c|}
\hline \multirow{2}{*}{$\begin{array}{c}\text { Etapas } \\
\mathrm{e} \\
\text { Modalidades }\end{array}$} & \multicolumn{5}{|c|}{ VARIAÇÕES ANUAIS } \\
\hline & $2008-2009$ & $2009-2010$ & $2010-2011$ & 2011-2012 & 2012-2013 \\
\hline $\begin{array}{c}\text { Ensino } \\
\text { Fundamental }\end{array}$ & $11.561 .511,60$ & $-40.056 .062,09$ & $35.364 .817,38$ & $-4.847 .388,05$ & $-18.098 .617,34$ \\
\hline $\begin{array}{l}\text { Educação } \\
\text { Infantil }\end{array}$ & $13.453 .918,54$ & $56.151 .510,08$ & $510.690,01$ & $-1.793 .275,80$ & $-20.948 .477,76$ \\
\hline $\begin{array}{l}\text { Educação } \\
\text { Especial }\end{array}$ & $-693.776,40$ & $421.048,88$ & $801.736,19$ & $-1.569 .822,84$ & $415.648,61$ \\
\hline $\begin{array}{c}\text { Educação } \\
\text { de Jovens e } \\
\text { Adultos }\end{array}$ & - & - & $303.777,31$ & $-170.972,19$ & $-63.407,32$ \\
\hline $\begin{array}{l}\text { Outros (Apoio } \\
\text { administrativo) }\end{array}$ & $-567.142,47$ & $907.859,04$ & $126.180,22$ & $1.482 .772,35$ & $30.623 .511,04$ \\
\hline $\begin{array}{c}\text { Valorização e } \\
\text { Capacitação } \\
\text { dos servidores }\end{array}$ & - & - & $-84.037,53$ & - & - \\
\hline TOTAL & $23.754 .511,26$ & $17.863 .176,76$ & $37.023 .163,58$ & $-6.967 .151,94$ & $-8.071 .342,77$ \\
\hline
\end{tabular}

Fonte: LOA, Vitória 2008, 2009, 2010, 2011, 2012 e 2013. Elaboração própria.

Valores atualizados com base no INPC/IBGE de 12/2014

Observamos, nas Tabelas 2 e 3, que os valores direcionados às etapas e modalidades apresentaram oscilações significativas entre si, durante o período de 2008 a 2013. O Ensino Fundamental teve, de 2008 para 2009, aumento de 6\% (aproximadamente R\$ 12 milhões); de 2009 para 2010, teve decréscimo de 
aproximadamente R \$ 40 milhões (18\%); de 2010 para 2011 teve aumento de 19\% (aproximadamente R $\$ 35$ milhões); de 2011 para 2012 teve decréscimo de aproximadamente R $\$ 5$ milhões (2\%); e de 2012 para 2013 também decréscimo, de $8 \%$ (aproximadamente 18 milhões de reais).

A Educação Infantil apresentou trajetória ascendente de 2008 a 2011. De 2008 para 2009, de 14\%; de 2009 para 2010, de 52\%; de 2010 para 2011, de $0,3 \%$. Contudo, nos dois períodos subsequentes apresentou decréscimo: de 1\% (aproximadamente R \$ 1,7 milhões), de 2011 a 2012; e de 13\% (aproximadamente $\mathrm{R} \$ 21$ milhões) de 2012 a 2013.

O valor destinado à Educação Especial variou nesse período, apresentando decréscimo de 33\% ( $\$$ \$ 693.776,40) de 2008 para 2009; aumento de 30\% (R\$ 421.048,88) de 2009 para 2010; aumento de 43\% ( $\$$ \$ 801.736,19) de 2010 para 2011; decréscimo de 59\% (1.569.822,84) de 2011 para 2012; e aumento de 38\% (R\$ 415.648,61) de 2012 para 2013.

Assim, por meio da análise da LOA, observamos que a Educação Especial receberia, no ano de 2008, 0,7\%, em 2009, 0,4\%, em 2010, 0,5\%, em 2011, 0,6\%, em 2012, 0,3\%, e em 2013, 0,4\% da parcela do total previsto para todas as etapas da Educação Básica e modalidades, bem como para a formação dos profissionais do magistério da rede municipal de ensino de Vitória. Desse modo, verificamos, nesse documento, a diminuição do percentual que seria despendido à Educação Especial de 2008 a 2013, embora o número de matrículas do público da Educação Especial (906 em 2008, 1.061 em 2009, 1.308 em 2010, 1.320 em 2011, 1.362 em 2012 e 1.181 em 2013) no município tenha apresentado uma trajetória crescente nesse período (exceto no ano de 2013), com um aumento de 30\%.

Diante desse contexto, no qual há crescimento de matrículas na Educação Especial e, ao mesmo tempo, redução do montante a ser destinado a sua manutenção e a seu funcionamento, consideramos que os recursos previstos para essa modalidade no planejamento orçamentário podem ter sofrido cortes por parte do governo, estar subestimados ou estar agregados aos valores destinados às outras etapas de ensino. Essa conjuntura de redução de verbas ou de problemas na gestão dos recursos destinados à Educação Especial também nos ajuda a compreender o porquê de não encontrarmos, nos documentos, alusão a novas contratações de profissionais e a novas construções no âmbito da Educação Especial, tampouco a ações para a expansão no atendimento educacional especializado no âmbito do município.

Os valores destinados à administração da Seme-Vitória, cerca de R \$ 4 milhões em 2008 e 2009, de R 5 milhões em 2010 e 2011, de R $\$ 6$ milhões em 2012 e R \$ 37 milhões em 2013 foram superiores aos direcionados às modalidades de ensino no município. Cabe acrescentar que nessa categoria ("Outros - apoio 
administrativo"), estavam previstos recursos para os espaços não formais da Seme-Vitória, fazendo com que houvesse um aumento nos valores orçados para esse fim.

Observamos, ainda, na LOA, a ausência de dados financeiros referentes à EJA nos anos de 2008 e de 2009. Vale ressaltar que, de acordo com os dados do Censo Escolar de 2008 e 2009, havia matrículas na EJA na rede municipal de ensino de Vitória. Nesse sentido, perguntamo-nos como foram custeadas as despesas para a manutenção das escolas que atendiam o público dessa modalidade de ensino nesses respectivos anos, tendo em vista que não foram previstos na LOA valores para esse fim. Destacamos que somente a partir do ano de 2010 há a criação de rubricas direcionadas à EJA. Assim, evidenciamos que a EJA receberia no ano de 2010, 0,08\%, em 2011, 0,15\%, em 2012,0,10\%, e em 2013,0,09\% da parcela do total previsto para todas as etapas da educação básica e modalidades.

Faz-se necessário ressaltar, ainda, que não foram fixados recursos destinados à formação continuada para os servidores que atuavam nas etapas e modalidades de ensino na rede de ensino do município em 2008, 2009, 2012 e 2013. Cumpre destacar que também havia registros de ações voltadas à formação continuada nos relatórios da Seme-Vitória, nesses respectivos anos. Esses dados somente foram registrados em 2010 ( $\mathrm{R} \$ 152.502,94)$ e 2011 ( $\mathrm{R} \$ 152.502,94)$. Entretanto, não encontramos nenhuma legislação nacional ou municipal sobre prestação de contas públicas que orientasse tal procedimento ou alteração.Desse modo, com base nos dados, consideramos que os recursos destinados a EJA e formação continuada dos servidores estavam agregados aos valores destinados às outras etapas de ensino.

\section{PLANEJAMENTO ORÇAMENTÁRIO DO MUNICÍPIO DE VITÓRIA: O LUGAR DA EDUCAÇÃO ESPECIAL ENTRE DISPUTAS E NEGOCIAÇÕES}

A análise do PPA, da LDO e da LOA nos possibilitou observar que a Educação Especial integrava a agenda educacional no município de Vitória, partindo do pressuposto de que, para a efetivação de uma política pública, como a de educação especial, é necessário que ela esteja presente no planejamento do Estado, que, por sua vez, constitui espaço de correlações de forças (SALVADOR 2010; OLIVEIRA, 2001).

Assim, acreditamos que o fato de a Educação Especial estar prescrita nos documentos de planejamento orçamentário pode demonstrar a intenção do município de investir nessa modalidade de ensino ou pode representar a existência de grupos sociais que, de certa forma, conseguiram, no âmbito do 
processo de discussão e elaboração desses documentos, que a educação especial fosse contemplada no planejamento do município.

Os documentos (PPA, LDO e LOA) referentes ao planejamento e à execução orçamentária do município de Vitória nos possibilitaram verificar, ainda, os rumos previstos para a educação nos períodos de 2006 a 2009 e de 2010 a 2013, e para onde seriam direcionados os recursos da educação. Nesse sentido, a prioridade era garantir a universalização do acesso à educação às crianças, adolescentes, jovens e adultos, bem como sua permanência na escola. E os valores previstos estavam voltados para as etapas da Educação Básica (Educação Infantil e Ensino Fundamental) e suas modalidades (Educação Especial e EJA), assim como para o apoio administrativo e a valorização e capacitação dos servidores.

Cabe ressaltar, ainda, que é nesse âmbito de planejamento orçamentário que ocorre a disputa política pelo fundo público, bem como o delineamento das prioridades do governo para os níveis e modalidades de ensino; portanto, são escolhas políticas que refletem a correlação de forças atuantes na sociedade (SALVADOR, 2010). Assim, faz-se necessário destacar a importância da participação da sociedade civil nesses espaços públicos de negociações e decisões no âmbito do Estado, seja na discussão e elaboração da proposta orçamentária, em que essa sociedade possa explicitar suas necessidades e demandas relacionadas às etapas e modalidades de ensino, de modo a incluí-las no planejamento orçamentário, seja no controle dos recursos públicos destinados à educação.

Essa participação política no planejamento e na gestão dos sistemas educacionais brasileiros pode ser viabilizada por meio de mecanismos de diálogo e democratização existentes, tais como os conselhos de educação (Conselho Escolar, Conselho de Alimentação Escolar, Conselho de Acompanhamento e Controle Social do Fundeb), o orçamento participativo, entre outros espaços públicos, numa perspectiva de gestão democrática da educação. Nesse sentido, o planejamento orçamentário constitui um processo amplo e complexo de tomadas de decisão e de disputas políticas, envolvendo uma pluralidade de atores com interesses diversos que, por sua vez, podem interferir na elaboração e na execução do orçamento.

Cabe ressaltar, ainda, que é nesse âmbito, o de planejamento orçamentário, que ocorre a disputa política pelo fundo público, bem como o delineamento das prioridades do governo para os níveis e modalidades de ensino; são, portanto, escolhas políticas que refletem a correlação de forças atuantes na sociedade.

Partindo do pressuposto de que a efetivação de uma política pública pressupõe sua presença no planejamento do Estado, que, por sua vez, constitui um espaço de correlação de forças, acreditamos que a Educação Especial, ao estar prescrita nos documentos de planejamento estatal, pode demonstrar a intenção 
do município de investir nessa modalidade de ensino ou pode representar a existência de grupos sociais que, de certa forma, conseguiram, no âmbito do processo de discussão e elaboração desses documentos, que a Educação Especial fosse contemplada no planejamento orçamentário do município.

\section{REFERÊNCIAS}

ADRIÃO, Theresa; CAMARGO, Rubens Barbosa de. A gestão democrática na Constituição Federal, de 1988. In: OLIVEIRA, Romualdo Portela de; ADRIÃO, Theresa (orgs.). Gestão Financiamento e direito à Educação: análise da Constituição Federal e da LDB. $3^{a}$ ed. São Paulo: Xamã, 2007. p. 63-72.

BRASIL. Lei $n^{\circ}$ 13.005, 25 de junho de 2014. Aprova o Plano Nacional de Educação - PNE e dá outras providências. Diário Oficial [da] República Federativa do Brasil, Brasília, 26 jun. 2014. Seção 1, p.1.

. Decreto no.7.611, de 17 de novembro de 2011. Dispõe sobre a educação especial, o atendimento educacional especializado e dá outras providências. Brasília: Presidência da República, 2011. Diário Oficial [da] República Federativa do Brasil, Brasília, 18 nov. 2011a. Seção 1, p. 12.

. Lei n ${ }^{\circ} 12.527$, de 18 de novembro de 2011. Regula o acesso a informações previsto no inciso XXXIII do art. 5o, no inciso II do \3o do art. 37 e no $\int 20$ do art. 216 da Constituição Federal; altera a Lei no 8.112, de 11 de dezembro de 1990; revoga a Lei no 11.111, de 5 de maio de 2005, e dispositivos da Lei no 8.159, de 8 de janeiro de 1991; e dá outras providências. Diário Oficial [da] República Federativa do Brasil, Brasília, 18 nov. 2011b.

Política Nacional de Educação Especial na Perspectiva da Educação Inclusiva. Brasil: MEC/SEESP, 2008.

. Decreto nº.6.094, de 24 de abril de 2007. Dispõe sobre a implementação do Plano de Metas Compromisso Todos pela Educação, pela União Federal, em regime de colaboração com Municípios, Distrito Federal e Estados, e a participação das famílias e da comunidade, mediante programas e ações de assistência técnica e financeira, visando à mobilização social pela melhoria da qualidade da educação básica. Diário Oficial [da] República Federativa do Brasil, Brasília, 25 abr. 2007a. Seção 1, p. 5. 
O Plano de Desenvolvimento da Educação: razões, princípios e programas. Brasília: MEC, 2007b.

. Lei no 11.274 , de 6 de fevereiro de 2006. Altera a redação dos arts. 29, 30, 32 e 87 da Lei no .9.394, de 20 de dezembro de 1996, que estabelece as diretrizes e bases da educação nacional, dispondo sobre a duração de 9 (nove) anos para o ensino fundamental, com matrícula obrigatória a partir dos 6 (seis) anos de idade. Diário Oficial [da] República Federativa do Brasil, Brasilia, 7 fev. 2006. Seção 1, p.1.

. Lei no 11.274 , de 6 de fevereiro de 2006. Altera a redação dos arts. 29, 30, 32 e 87 da Lei no .9 .394 , de 20 de dezembro de 1996, que estabelece as diretrizes e bases da educação nacional, dispondo sobre a duração de 9 (nove) anos para o ensino fundamental, com matrícula obrigatória a partir dos 6 (seis) anos de idade. Diário Oficial [da] República Federativa do Brasil, Brasilia, 7 fev. 2006a. Seção 1, p.1.

Lei Complementar n.101, de 04 de maio de 2000. Estabelece normas de finanças públicas voltadas para a responsabilidade na gestão fiscal e dá outras providências. Diário Oficial [da] República Federativa do Brasil, Brasília, 4 mai. 2000.

Lei de Diretrizes e Bases da Educação Nacional- LDBn.9.394, de 20 de dezembro de 1996. Diário Oficial [da] República Federativa do Brasil, Brasília, 23 dez. 1996.

Federal, 1988.

.Constituição [da] República Federativa do Brasil. Brasília: Senado

.Lei no 4.320, de 17 de março de 1964.Estatui normas gerais de direito financeiro para elaboração e controle dos orçamentos e balanços da União, dos Estados, dos Municípios e do Distrito Federal. Diário Oficial [da] República Federativa do Brasil. Brasília, 1964.

CURY, Carlos Roberto Jamil. Estado e políticas de financiamento em educação. Educação \& Sociedade, Campinas, v. 28, n. 100, p. 831-855, out. 2007.

FARENZENA, Nalú. A política de financiamento da educação básica: rumos da legislação brasileira. Porto Alegre, RS: UFRGS, 2006. 
GARCIA, Rosalba Maria Cardoso; MICHELS, Maria Helena. A política de educação especial no Brasil (1991-2011): uma análise da produção do GT15 educação especial na Anped. Revista Brasileira de Educação Especial. Marília, v. 17, p. 105-124, maio/ago. 2011.

GOUVEIA, Andrea Barbosa. Orçamento participativo, controle social e o poder público municipal: a experiência de União da Vitória/PR (1997-2000). 2002. Dissertação (Mestrado em Educação) - Programa de Pós-Graduação em Educação, Universidade de São Paulo, 2002.

KASSAR, Monica de Carvalho Magalhães. Reforma do Estado e Educação Especial: preliminares para uma análise. Revista de Educação PUC-Campinas, Campinas, n. 11, p. 24-34, nov. 2001.

LAPLANE, Adriana Lia Frisman; PRIETO, Rosângela Gavioli. Inclusão, diversidade e igualdade na Conae 2010: perspectivas para o novo Plano Nacional de Educação. Educação \& Sociedade, Campinas, v. 31, n. 112, p. 919-938, jul./ set. 2010.

MELCHIOR, José Carlos de Araújo. Financiamento da educação: gestão democrática dos recursos financeiros públicos em educação. Revista Brasileira de Estudos Pedagógicos, Brasília, v.72, n. 172, p. 262-290, set./dez. 1991.

OLIVEIRA, Fabrício. Economia e política das finanças púbicas: uma abordagem critica da teórica convencional, à luz da economia brasileira. Belo Horizonte, 2001.

POLO, José Carlos. Planejamento e orçamento no município. In: PRASEM, FUNDESCOLA, MEC. Guia de consulta. Brasília: MEC, 1999, p. 295-329.

PLETSCH, Márcia Denise. Educação especial e inclusão escolar: uma radiografia do atendimento educacional especializado nas redes de ensino da Baixada Fluminense / RJ. Ciências Humanas e Sociais em Revista, Rio de Janeiro, EDUR, v. 34, n. 12, jan./jun., p. 31-48, 2012.

SALVADOR, Evilásio. Fundo público e o financiamento das políticas sociais no Brasil. Serviço Social em Revista, Londrina, n. 2, v. 14, p. 4-22, jan./jun. 2012. 
.Fundo público e seguridade social no Brasil. São Paulo: Cortez, 2010.

VITÓRIA. Lei n. 8.397, de 20 de dezembro de 2012. Estima a receita e fixa a despesa do município de Vitória para o exercício de 2013. 2012a Disponível em: < http://www.sistemas.vitoria.es.gov.br/webleis/arquivos/2009/17633.pdf>. Acesso em: 05 mai. 2012.

Lei n. 8.325, de 16 de julho de 2012. Dispõe sobre as diretrizes para a elaboração da lei orçamentária de 2013 e dá outras providências. 2012b. Disponível em: <http://www.sistemas.vitoria.es.gov.br/webleis/arquivos/2008/17527.pdf>. Acesso em: 05 mai. 2012.

Lei n. 8.202, de 22 de dezembro de 2011. Estima a receita e fixa a despesa do município de Vitória para o exercício de 2012. 2011. Disponível em: <http://www.sistemas.vitoria.es.gov.br/webleis/arquivos/2009/17633.pdf>. Acesso em: 05 mai. 2012.

Lei n. 8.136, de 15 de julho de 2011. Dispõe sobre as diretrizes para a elaboração da lei orçamentária de 2012 e dá outras providências. 2011a Disponível em: <http://www.sistemas.vitoria.es.gov.br/webleis/arquivos/2008/17527.pdf>. Acesso em: 05 mai. 2012.

Lei n. 7.973, de 22 de julho de 2010. Dispõe sobre as diretrizes para a elaboração da lei orçamentária de 2011 e dá outras providências. 2010a. Disponível em: < http://www.sistemas.vitoria.es.gov.br/webleis/arquivos/2008/17527.pdf>. Acesso em: 05 mai. 2012.

Lei n. 8.013, de 22 de novembro de 2010. Estima a receita e fixa a despesa do município de Vitória para o exercício de 2011. 2010b. Disponível em: <http://www.sistemas.vitoria.es.gov.br/webleis/arquivos/2009/17633.pdf>. Acesso em: 05 mai. 2012.

Lei n. 7.845, de 09 de dezembro de 2009. Dispõe sobre o Plano Plurianual - PPA para o período 2010/2013.2009a. Disponível em: < http:// www.legislacaoonline.com.br/vitoria/images/leis/html/178452009.html>. Acesso em: 05 mai. 2012.

. Lei n. 7.756, de 22 de julho de 2009. Dispõe sobre as diretrizes para a elaboração da lei orçamentária de 2010 e dá outras providências. 2009b. Disponível 
em: <http://www.sistemas.vitoria.es.gov.br/webleis/arquivos/2009/17756.pdf>. Acesso em: 05 mai. 2012.

Lei n. 7.847, de 17 de dezembro de 2009. Estima a receita e fixa a despesa do município de Vitória para o exercício de 2010.2009c. Disponível em: $<$ http:/ / www.sistemas.vitoria.es.gov.br/webleis/arquivos/2009/17847.pdf>. Acesso em: 05 mai. 2012.

Lei n. 7.527, de 07 de julho de 2008. Dispõe sobre as diretrizes para a elaboração da lei orçamentária de 2009 e dá outras providências. 2008a. Disponível em: <http://www.sistemas.vitoria.es.gov.br/webleis/arquivos/2008/17527.pdf>. Acesso em: 05 mai. 2012.

Lei n. 7.633, de 15 de dezembro de 2008. Estima a receita e fixa a despesa do município de Vitória para o exercício de 2009.2008b. Disponível em: <http://www.sistemas.vitoria.es.gov.br/webleis/arquivos/2009/17633.pdf $>$. Acesso em: 05 mai. 2012.

Lei $\mathbf{n}^{\mathbf{0}} \mathbf{6 . 9 4 8}$, de 13 de julho de 2007. Dispõe sobre as diretrizes para a elaboração da lei orçamentária de 2008 e dá outras providências. 2007. Disponível em: <http://sistemas.vitoria.es.gov.br/webleis/Arquivos/2007/L6948.PDF>. Acesso em: 5maio 2012.

Lei n. 6.375, de 14 de setembro de 2005. Dispõe sobre o Plano Plurianual - PPA para o período 2006/2009. 2005. Disponível em: < http:// sistemas/vitoria.es.gov.br/webleis/arquivos/2005/16375.pfd>. Acesso em: 05 mai. 2012.

MARILEIDE GONÇALVES FRANÇA possui graduação em Pedagogia pela Universidade Federal do Espírito Santo (2005), mestrado em Educação pela Universidade Federal do Espírito Santo (2008) e doutorado em Educação na Universidade de São Paulo (2014). Atua como pedagoga no Instituto Federal do Espírito Santo, Campus Cariacica. Tem experiência na área de Educação, com ênfase em Educação Especial, atuando principalmente nos seguintes temas: política educacional; financiamento da educação, formação de professores; planejamento educacional, avaliação educacional e inclusão escolar. E-mail: leidemary8@gmail.com 